\title{
An analytical system for the measurement of stable hydrogen isotopes in ambient volatile organic compounds
}

\author{
T. Meisehen, F. Bühler, R. Koppmann, and M. Krebsbach \\ Institute for Atmospheric and Environmental Research, University of Wuppertal, Wuppertal, Germany \\ Correspondence to: T. Meisehen (meisehen@uni-wuppertal.de)
}

Received: 1 May 2015 - Published in Atmos. Meas. Tech. Discuss.: 10 July 2015

Revised: 23 September 2015 - Accepted: 2 October 2015 - Published: 23 October 2015

\begin{abstract}
Stable isotope measurements in atmospheric volatile organic compounds (VOCs) are an excellent tool to analyse chemical and dynamical processes in the atmosphere. While up to now isotope studies of VOCs in ambient air have mainly focussed on carbon isotopes, we herein present a new measurement system to investigate hydrogen isotope ratios in atmospheric VOCs. This system, consisting of a gas chromatography pyrolysis isotope ratio mass spectrometer (GC-P-IRMS) and a preconcentration system, was thoroughly characterised using a VOC test mixture. A precision of better than $9 \%$ (in $\delta^{2} \mathrm{H}$ ) is achieved for $n$-pentane, 2-methyl-1,3-butadiene (isoprene), $n$-heptane, 4-methyl-pentane-2-one (4-methyl-2pentanone), methylbenzene (toluene), $n$-octane, ethylbenzene, $m / p$-xylene and 1,2,4-trimethylbenzene. A comparison with independent measurements via elemental analysis shows an accuracy of better than $9 \%$ for $n$-pentane, $n$ heptane, 4-methyl-2-pentanone, toluene and $n$-octane. Above a minimum required pre-concentrated compound mass the obtained $\delta^{2} \mathrm{H}$ values are constant within the standard deviations. In addition, a remarkable influence of the pyrolysis process on the isotope ratios is found and discussed. Reliable measurements are only possible if the ceramic tube used for the pyrolysis is sufficiently conditioned, i.e. the inner surface is covered with a carbon layer. It is essential to verify this conditioning regularly and to renew it if required. Furthermore, influences of a necessary $\mathrm{H}_{3}^{+}$correction and the pyrolysis temperature on the isotope ratios are discussed. Finally, the applicability to measure hydrogen isotope ratios in VOCs at ambient levels is demonstrated with measurements of outside air on 5 different days in February and March 2015. The measured hydrogen isotope ratios range from -136 to $-105 \%$ for $n$-pentane, from -86 to $-63 \%$ for toluene,
\end{abstract}

from -39 to $-15 \%$ for ethylbenzene, from -99 to $-68 \%$ o for $m / p$-xylene and from -45 to $-34 \%$ ofor $o$-xylene.

\section{Introduction}

Isotope effects in nature provide fingerprints of physical and chemical processes, which are often difficult to quantify. The ratios of stable isotopes in trace constituents in the atmosphere are altered in almost all processes they are involved in, such as chemical reactions, thermodynamic equilibration, diffusion, phase transitions, photolytic processes and isotope exchange reactions. The large variety of possible applications ranges from the reconstruction of past climates to the investigation of current physical and chemical processes in the atmosphere.

The application of isotope ratio studies in atmospheric volatile organic compounds (VOCs) at ambient concentrations (ppbV and even pptV levels) is a relatively recent development (Rudolph et al., 1997). It opened the possibility to study isotopic signatures of ambient organic compounds, to investigate their sources, photochemical histories and residence times $\left(\mathrm{C}_{2}-\mathrm{C}_{8}\right.$ hydrocarbons, aromatics, methyl halides, chlorofluorocarbon(CFC) and 2-methyl-1,3-butadiene - isoprene) (Tsunogai et al., 1999; Saito et al., 2002; Rudolph et al., 2002, 2003; Thompson, 2003; Archbold et al., 2005; Saito et al., 2009; Redeker et al., 2007). Goldstein and Shaw (2003) and Gensch et al. (2014) reviewed available information on stable carbon isotope ratios of VOCs and the possibility of using isotope ratio measurements to study atmospheric budgets of VOCs. The applications in atmospheric chemistry were reviewed by Brenninkmeijer et al. (2003). Measurements of stable isotope ratios in VOCs allow one to inves- 
tigate physical and chemical processes on a wide range of temporal and spatial scales (micro-scale processes, exchange processes between different atmospheric regions, both horizontally and vertically, large-scale transport processes and interdependencies between different compartments of the Earth system). Such studies provide valuable information on the dominant processes on these scales, since VOCs have highly variable atmospheric lifetimes (hours to months) and different sources (biogenic, anthropogenic, chemical reactions in the atmosphere) (Rudolph, 2007). Furthermore, VOCs are useful tracers to investigate reactions that are not directly accessible to current measurement techniques or as probes to visualise transport and mixing processes (also in case of rapid mixing) in the atmosphere or across atmospheric boundaries.

However, to our knowledge up to now almost all studies concerning ambient VOCs concentrated on carbon isotope ratios. In principle, the investigation of isotope ratios of other elements can further improve our understanding of atmospheric processes by adding additional pieces of information. Measurements of ${ }^{2} \mathrm{H} /{ }^{1} \mathrm{H}$ would be especially promising. Hydrogen isotope effects will be more pronounced than carbon isotope effects because of the larger mass ratio of ${ }^{2} \mathrm{H} /{ }^{1} \mathrm{H}$ than that of ${ }^{13} \mathrm{C} /{ }^{12} \mathrm{C}$ leading to larger kinetic isotope effects (KIEs) of hydrogen compared to carbon (Iannone et al., 2004, 2005; Gensch et al., 2014).

Owing to the much lower isotope abundances of ${ }^{2} \mathrm{H}$ (0.015\%; De Biévre et al., 1984) compared to ${ }^{13} \mathrm{C}(1.1 \%$; De Biévre et al., 1984), significant larger sample volumes ( $\sim 200 \mathrm{~L}$, instead of $\sim 20 \mathrm{~L}$ for carbon) are needed to obtain adequate signal-to-noise ratios in the isotope ratio mass spectrometer. Regarding the expected $\delta^{2} \mathrm{H}$ values of atmospheric VOCs $(-290$ to $-140 \%$ ) based on published studies of source rocks, crude oil, sediments, plant waxes and aerosol particles (Xiong et al., 2005; Liu et al., 2006; Yeh and Epstein, 1981; Duan et al., 2011; Bi et al., 2005; Yamamoto and Kawamura, 2010; Greule et al., 2012) and the few known KIEs $(\sim 10$ to $\sim 100 \%$; Iannone et al., 2004, 2005), stable hydrogen isotope ratios should at least be measured with a precision (in terms of $\delta$-values) of $10-20 \%$ to identify isotope effects. For measurements of hydrogen isotope ratios in atmospheric VOC at ambient concentrations, the currently available sample preparation techniques have to be modified to allow for the analysis of a large volume whole air samples. Furthermore, it has to be ensured that the analysis can be done with sufficient sensitivity and precision to identify changes in hydrogen isotope ratios occurring in atmospheric processes.

Recently, two studies were published using both $\delta^{13} \mathrm{C}$ and $\delta^{2} \mathrm{H}$ measurements of selected VOCs under specific conditions (von Eckstaedt et al., 2011a, b). The authors applied a gas chromatograph pyrolysis isotope ratio mass spectrometer (GC-P-IRMS) to investigate stable isotope ratios in emissions from biomass combustion, the exhaust from diesel and petrol cars, and from an aluminium industry stack.
They obtained $\delta^{2} \mathrm{H}$ values for a variety of VOCs, but obviously at rather high concentrations compared to atmospheric conditions. Their $\delta^{2} \mathrm{H}$ values ranged from -280 to $+30 \%$. Another very recent study concerning benzene and methylbenzene (toluene) emissions from cars (Kikuchi and Kawashima, 2013) obtained $\delta^{2} \mathrm{H}$ values in these compounds ranging from -159.5 to -25.6 and -59.2 to $-19.3 \%$, respectively. They compared their source measurements with ambient samples taken at a roadside. Here they found $\delta^{2} \mathrm{H}$ values of -174.4 to -74.9 and -134.7 to $-35.0 \%$ o for benzene and toluene, respectively, which indicates an impact of the sources to the ambient values. These measurements seem to be the only available $\delta^{2} \mathrm{H}$ values of VOCs in ambient air so far. Another study on ambient VOCs is reported by Rice and Quay (2009). However, their study solely focusses on formaldehyde. These studies showed that it is generally possible to measure $\delta^{2} \mathrm{H}$ values of VOCs with considerable precision. To our knowledge, there are no other measurements of stable hydrogen isotope ratios in atmospheric VOCs reported up to now.

In this paper we describe a method for measurements of $\delta^{2} \mathrm{H}$ of atmospheric VOCs based on a modification of existing methods for the measurement of $\delta^{13} \mathrm{C}$ in atmospheric VOCs (see Iannone et al., 2007; Wintel et al., 2013).

\section{Experimental set-up}

Hydrogen isotope ratios were measured by a GC-P-IRMS in continuous flow mode. The system consists of four main components: (1) a pre-concentration unit designed for high volume whole air samples, (2) a gas chromatograph coupled to a quadrupole mass spectrometer, (3) a pyrolysis unit, and (4) an isotope ratio mass spectrometer. Figure 1 schematically shows the set-up of the GC-P-IRMS. The total analysis time for one measurement is $180 \mathrm{~min}$ for VOCs preconcentrated from a volume of $50 \mathrm{~L}$ of air for the characterisation measurements.

\subsection{Sample preparation}

VOCs are extracted from the air sample and pre-concentrated using a specifically designed cryo-focussing system (TDSGL; Gerstel GmbH and Co.KG, Mühlheim a.d.R., Germany). It consists of two unpacked traps (traps $1+2$ ), a thermal desorption system (TDS), followed by two further unpacked traps (traps $3+4$ ) and finally a cold injection system (CIS) and a cryo-trap system (CTS) (see Fig. 1). All traps as well as the TDS are stainless steel tubes with a length of $52.5 \mathrm{~cm}$ (ID $12 \mathrm{~mm}$ ), of $30 \mathrm{~cm}$ (ID $12 \mathrm{~mm}$ ) and of $11 \mathrm{~cm}$ (ID $5 \mathrm{~mm}$ ) for the TDS, traps $1+2$ and traps $3+4$, respectively. The CIS consists of a glass liner (length $68 \mathrm{~mm}$, ID $1.7 \mathrm{~mm}$ ) packed with glass beads $(60 / 80$ mesh) and allows for cooling and heating at a high rate $\left(12 \mathrm{~K} \mathrm{~s}^{-1}\right)$. The CTS is placed at the beginning $(85 \mathrm{~mm})$ of the first chromatographic column, lo- 

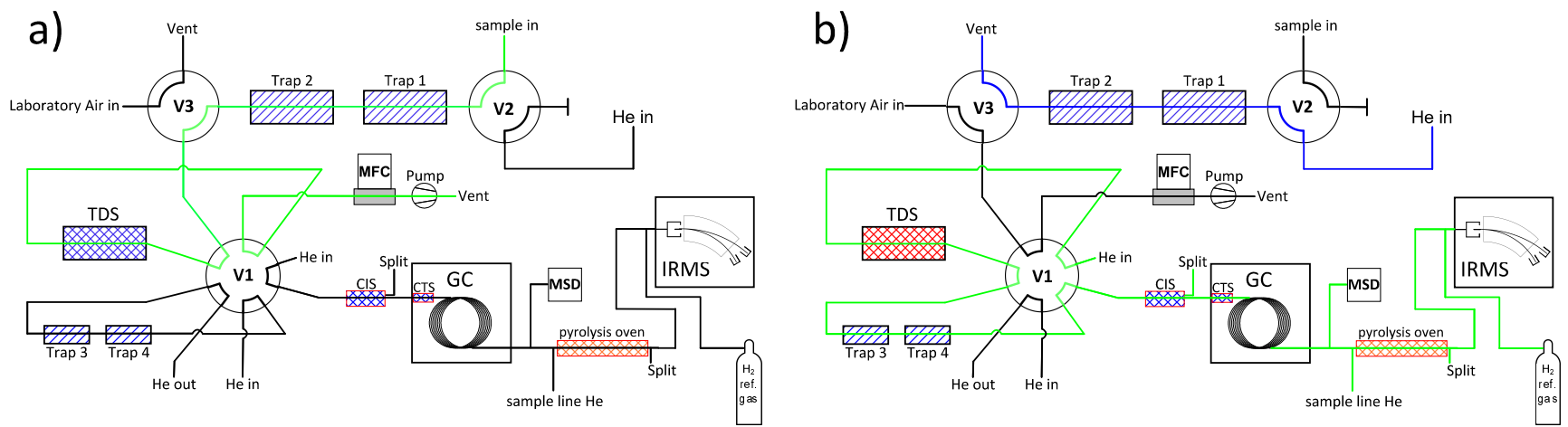

Figure 1. Schematic of the measurement system in the pre-concentration mode (a): the sample volume is drawn through traps $1+2$ (reduction of water) and TDS, where the VOCs are trapped. A sample gas stream is represented by the green line. System in transfer mode (b): the sample is desorbed from TDS through traps $3+4$ (water reduction) to CIS and CTS for cryogenic focussing. After desorption from the CTS the VOCs are chromatographically separated and detected in the MSD as well as in the IRMS after passing the pyrolysis oven. The sample gas stream is represented as a green line, whereas the blue line shows a helium flow for purging the TDS and traps $1+2$ after desorption. See text for more detail.

cated inside the gas chromatography (GC) oven. It allows for a rapid cooling and heating $\left(12 \mathrm{~K} \mathrm{~s}^{-1}\right)$ of a $5 \mathrm{~cm}$ long section of the capillary. To avoid wall losses, the TDS and all traps are Sulfinert ${ }^{\circledR}$ coated (Restek GmbH, Bad Homburg, Germany). All temperatures are individually controlled by a combination of cooling by liquid nitrogen and electrical heating.

During the experiments, two different configurations of the TDS were tested. In the first configuration (A), the TDS was packed with glass beads $(60 / 80$ mesh), on which the VOCs were cryogenically trapped. In this configuration TDS temperatures were set to 103 and $503 \mathrm{~K}$ for adsorption and desorption, respectively. In the second configuration (B) the VOCs were extracted from the sample using Tenax ${ }^{\circledR} \mathrm{TA}$ (Sigma-Aldrich Chemie GmbH, Taufkirchen, Germany). In this configuration temperatures were set to 272 and $573 \mathrm{~K}$ for adsorption and desorption, respectively. The advantage of Tenax ${ }^{\circledR} \mathrm{TA}$ is the very low break through volume for water and especially for $\mathrm{CO}_{2}$ (Helmig and Vierling, 1995) and therefore it has widely been used for sampling atmospheric VOCs (see for example Rudolph et al., 1990). This reduces significantly the amount of $\mathrm{CO}_{2}$ in the pre-concentrated sample, thus preventing the CTS from freezing over which was frequently observed when VOCs where pre-concentrated on glass beads.

In both configurations the sample is drawn through traps 1 and 2 and the TDS for 50 min with a mass flow of $1000 \mathrm{~mL} \mathrm{~min}^{-1}$ using a rotary pump. The sample volume can be altered by varying the time of the pre-concentration step or the flow rate. The volume of the whole air sample for all characterisation measurements presented here was $\sim 50 \mathrm{~L}$. Traps 1 and 2 are used to reduce water from the atmospheric samples at $253 \mathrm{~K}$ prior to pre-concentrating the VOCs on the adsorbent within the TDS at the respective adsorption temperature (depending on the packing material). Valves 1, 2 and 3 are in pre-concentration position at this step (cf. Fig. 1a). In configuration $\mathrm{A}, \mathrm{H}_{2} \mathrm{O}$ and $\mathrm{CO}_{2}$ are also partially trapped because of the low TDS temperature; in configuration $\mathrm{B} \mathrm{CO}_{2}$ and most of $\mathrm{H}_{2} \mathrm{O}$ are mainly exhausted with the bulk air. In the next step, valve 2 is switched to the transfer position to flush the TDS with helium for $2 \mathrm{~min}$. After this, valves 1 and 3 are also switched to transfer position and the desorbed VOCs pass through two additional traps (traps 3 and 4 ) to the CIS (cf. Fig. 1b). At that time the TDS is heated up to the respective desorption temperature (depending on the packing material) at a rate of $40 \mathrm{~K} \mathrm{~min}^{-1}$. The VOCs are desorbed for $20 \mathrm{~min}$ with a helium flow rate of $110 \mathrm{~mL} \mathrm{~min}^{-1}$ and focussed on the CIS at $103 \mathrm{~K}$. Traps 3 and 4 are set to $243 \mathrm{~K}$ and used to further reduce $\mathrm{H}_{2} \mathrm{O}$ following the pre-concentration step (Thompson, 2003). To avoid any wall losses all transfer lines in the TDSG-L are held at $393 \mathrm{~K}$. In a last focussing step the VOCs are desorbed in a splitless mode from the CIS with a flow rate of $4 \mathrm{~mL} \mathrm{~min}^{-1}$ by heating it to $523 \mathrm{~K}$ at a rate of $12 \mathrm{~K} \mathrm{~s}^{-1}$ and trapped on the CTS at $103 \mathrm{~K}$. After $3 \mathrm{~min}$ the VOCs are desorbed by heating the CTS to $503 \mathrm{~K}$ at a rate of $12 \mathrm{~K} \mathrm{~s}^{-1}$, which marks the start of the chromatographic separation.

During the chromatographic separation, the preconcentration system is purged for $60 \mathrm{~min}$ with helium at a flow rate of $400 \mathrm{~mL} \mathrm{~min}^{-1}$ by switching valves 1 and 3 and heating all traps and transfer lines to $393 \mathrm{~K}$ (the TDS to $573 \mathrm{~K}$ ). After the desorption of the VOCs from the CTS, the CIS is purged with helium by using the solvent vent mode of the GC. The helium used in the whole process is He 5.0 (Messer Industriegase GmbH, Bad Soden, Germany) purified by a Restek Super Clean ${ }^{\circledR}$ Gas Filter to better than He 6.0 (purity $99.9999 \%$ ). 


\subsection{Gas chromatograph and mass selective detector}

The VOCs are separated by gas chromatography (GC 7890A, Agilent Technologies Inc., Santa Clara, CA, USA) using a two-column combination consisting of a non-polar Rtx ${ }^{\circledR}-1$ (Restek GmbH) column (105 m, $0.32 \mathrm{~mm}$ ID, $3 \mu \mathrm{m} \mathrm{d} f$ ) followed by a mid-polarity Crossbond ${ }^{\circledR}$ phase $\mathrm{Rxi}^{\circledR}-624$ Sil MS (Restek GmbH) column (60 m, $0.32 \mathrm{~mm}$ ID, $1.8 \mu \mathrm{m} \mathrm{d} f$ ). Using helium as the carrier gas, the initial GC temperature is $233 \mathrm{~K}$ (cooled with $\mathrm{LN}_{2}$ and held isothermal for $12 \mathrm{~min}$ ) and increased at a rate of $4 \mathrm{Kmin}^{-1}$ to a temperature of $473 \mathrm{~K}$ (held for $1 \mathrm{~min}$ ). The oven temperature is then finally increased to $503 \mathrm{~K}$ at a rate of $20 \mathrm{Kmin}^{-1}$. The flow rate through the columns is kept constant at $4 \mathrm{~mL} \mathrm{~min}^{-1}$ during the whole temperature programme. Following separation, a minor part of the eluent is directed to the mass selective detector, the major part to the pyrolysis oven and the isotope ratio mass spectrometer (IRMS) (split ratio approx. 1:9).

A mass selective detector (MSD; quadrupole mass analyser 5975C, Agilent Technologies Inc., Santa Clara, CA, USA) allows for identification and quantification of the compounds. The MSD is operated at a measurement frequency of about $7 \mathrm{~Hz}$ and a mass range of $15-200 \mathrm{u}$. The quadrupole was kept at a temperature of $423 \mathrm{~K}$, the source temperature was kept at $503 \mathrm{~K}$. While the MSD is currently only used for identification during the characterisation measurements it will also be used to quantify substances when measuring unknown air samples.

\subsection{Pyrolysis oven}

In the pyrolysis oven (GC 5, Isoprime Ltd., Manchester, UK), the VOCs are decomposed and the hydrogen atoms recombine to hydrogen molecules. During first tests, we used a quartz tube (ID $\sim 0.5 \mathrm{~mm}$ ) packed with chromium pellets, operated at $1273 \mathrm{~K}$, for pyrolysis of the VOCs. Because the quartz tube was blocked obviously with elemental carbon after only a few measurements, it was replaced by a ceramic tube (ID $\sim 0.5 \mathrm{~mm}$ ) which is operated at a temperature of $1723 \mathrm{~K}$. This turned out to be the optimum temperature with respect to reproducible isotope ratio measurements (see Sect. 3.3.2). The resulting ${ }^{1} \mathrm{H}_{2}$ and ${ }^{1} \mathrm{H}^{2} \mathrm{H}$ molecules are then transferred to the (sector field) IRMS via an open split and a $1 \mathrm{~m}$ deactivated fused silica capillary $(0.1 \mathrm{~mm}$ ID). To maintain a constant flow through the pyrolysis oven and to avoid back diffusion, an additional helium flow (sample line helium) of approximately $1 \mathrm{~mL} \mathrm{~min}^{-1}$ is added to the flow through the ceramic tube.

\subsection{Isotope ratio mass spectrometer}

The isotope ratio measurements are performed with the Isoprime 100 IRMS (Isoprime Ltd.). After ionisation the ions pass through the electric and magnetic fields and are collected by Faraday cups. The resulting signals yield two chro- matograms, one of ${ }^{1} \mathrm{H}_{2}$ (major signal) and one of ${ }^{1} \mathrm{H}^{2} \mathrm{H}$ (minor signal). From these data the $\delta^{2} \mathrm{H}$ values of the individual VOCs are determined with respect to the $\mathrm{H}_{2}$ working reference gas (Air Liquide GmbH, Düsseldorf, Germany) with a $\delta^{2} \mathrm{H}$ of $-261 \%$ vs. Vienna Standard Mean Ocean Water (VSMOW). The working reference gas is connected to the IRMS via a reference gas injector box (Isoprime Ltd.) and a second open split. It allows supplying working reference gas peaks at certain times. For this purpose a pneumatic valve controlled by the IRMS software is opened for $30 \mathrm{~s}$ for each working reference gas peak.

The $\delta^{2} \mathrm{H}$ values are determined as follows. For each peak, major and minor signals are integrated automatically by the software IonVantage Continuous Flow Data Processing (CFDP v. 1.4.9.0), correcting for the $\mathrm{H}_{3}^{+}$contribution (also see Sect. 3.4) (Sessions et al., 2001a, b). If necessary, the integration parameters peak start and peak end are adjusted manually. Finally, for each peak the ratios of mass $3\left({ }^{1} \mathrm{H}^{2} \mathrm{H}\right)$ to mass $2\left({ }^{1} \mathrm{H}_{2}\right)$ are calculated and converted to $\delta^{2} \mathrm{H}$ values with regard to VSMOW considering the working reference gas ${ }^{2} \mathrm{H} /{ }^{1} \mathrm{H}$ ratio by Eqs. (1) and (2), where $\left(\frac{{ }^{2} \mathrm{H}}{{ }^{1} \mathrm{H}}\right)$ sample and $\left(\frac{{ }^{2} \mathrm{H}}{{ }^{1} \mathrm{H}}\right)_{\text {ref. }}$ are the calculated mass ratios of the sample peak and the working reference gas peaks, respectively, and $\delta^{2} \mathrm{H}_{\text {ref.-VSMOW }}$ is the known $\delta^{2} \mathrm{H}$ value of the working reference gas with regard to VSMOW.

$\delta^{2} \mathrm{H}_{\text {raw }}=\frac{\left(\frac{{ }^{2} \mathrm{H}}{{ }^{\mathrm{H}} \mathrm{H}}\right)_{\text {sample }}-\left(\frac{{ }^{2} \mathrm{H}}{{ }^{1} \mathrm{H}}\right)_{\text {ref. }}}{\left(\frac{{ }^{2} \mathrm{H}}{{ }^{1} \mathrm{H}}\right)_{\text {ref. }}}$

$\delta^{2} \mathrm{H}=\delta^{2} \mathrm{H}_{\text {raw }}+\delta^{2} \mathrm{H}_{\text {ref.-vSMOW }}+\delta^{2} \mathrm{H}_{\text {raw }} \cdot \delta^{2} \mathrm{H}_{\text {ref.-vSMOW }}$

\subsection{VOC test mixture}

For the characterisation experiments a test mixture with known VOC mixing and isotope ratios is needed. We prepared a VOC test mixture by injecting 16 VOCs (see Table 1) from the liquid phase through a septum into a gas cylinder (Messer Industriegase $\mathrm{GmbH}$ ), which was finally pressurised with $\mathrm{N}_{2}$ to 60 bar. The final mixing ratios of the compounds range from 92 to $523 \mathrm{ppbV}$. As the mixing ratios of the VOCs in this test mixture are much higher than ambient levels, the VOC test mixture is diluted with purified synthetic air (purity $>6.0$ ) for every measurement to yield mixing ratios comparable to ambient air (about $1-10 \mathrm{ppbV}$ ). This is done with a dynamic dilution system (Hembeck, 2008) where the samples are additionally humidified (to a RH of about $48 \%$ at room temperature). The pure compounds, which were used to prepare the VOC test mixture, have been analysed independently for $\delta^{2} \mathrm{H}$ via elemental analysis (EA) by Agroisolab (Jülich, Germany). They injected about 1 to $2 \mu \mathrm{L}$ of the liquid sample into their analytical system consisting of an element analyser (Eurovector 3000) combined with an IRMS (Micromass, Manchester, UK). Their combustion tube filled with nickel oxide and elemental chromium was operated at 
$1323 \mathrm{~K}$. As internal laboratory standards three water samples covering the scale from 0 to $-100 \%$ were used which were calibrated with International Atomic Energy Agency Standard Mean Ocean Water (IAEA-SMOW), International Atomic Energy Agency -Greenland Ice Sheet Precipitation (IAEA-GISP) and International Atomic Energy Agency Standard Light Antarctic Precipitation (IAEA-SLAP).

Using the VOC test mixture our analytical system was thoroughly tested, especially with respect to possible fractionation effects during sample pre-concentration and analysis. In addition the measured $\delta^{2} \mathrm{H}$ values were compared to the results obtained by Agroisolab.

\section{Results of the characterisation experiments}

The system as described above was characterised with respect to (1) the suitability of the adsorbent material in the TDS, (2) reproducibility, stability, linearity and detection limit, (3) an influence of the pyrolysis on the $\delta^{2} \mathrm{H}$ values and (4) an influence of the $\mathrm{H}_{3}^{+}$correction on the $\delta^{2} \mathrm{H}$ values. All measurements described in the following were performed with the VOC test mixture diluted with purified synthetic air (dilution $1: 76$ ). An example of a typical chromatogram measured by the IRMS is shown in Fig. 2. At the beginning of each chromatogram, five measurements of the working reference gas were performed. At the end of each chromatogram, the working reference gas was measured again (2 peaks). Using the GC programme described above, we are able to analyse 10 of the 16 compounds contained in the VOC test mixture for hydrogen isotope ratios. Methanol, acetone, pentanal, propanal and hexanal cannot be analysed due to too small peak areas or to an influence by a water background at retention times lower than $3800 \mathrm{~s}$. Moreover, no isotope values for benzene are presented because Tenax ${ }^{\circledR} \mathrm{TA}$ produces a significant benzene background. This effect was already observed in previous studies (De Bortoli et al., 1992). With the exception of $n$-pentane and isoprene the peaks of all other compounds presented here were baseline separated with peak areas of 5 to $50 \mathrm{nAs}$ (major signal) and can thus reliably be analysed. All results presented in the following are mean values calculated from a set of individual measurements. Furthermore, the standard deviations are calculated and corrected with the $t$ factor considering Student's $t$ distribution because of the limited number of individual data points.

\subsection{Adsorbent material in the TDS}

As stated above, two different configurations of the TDS were used. Initially, we used the TDS packed with glass beads (configuration A). However, when analysing ambient air, measurements using the TDS in this configuration are limited to a sample volume of about $30 \mathrm{~L}$ because of the high amount of $\mathrm{CO}_{2}$ (at $400 \mathrm{ppmV}$ this corresponds to $24 \mathrm{mg}$

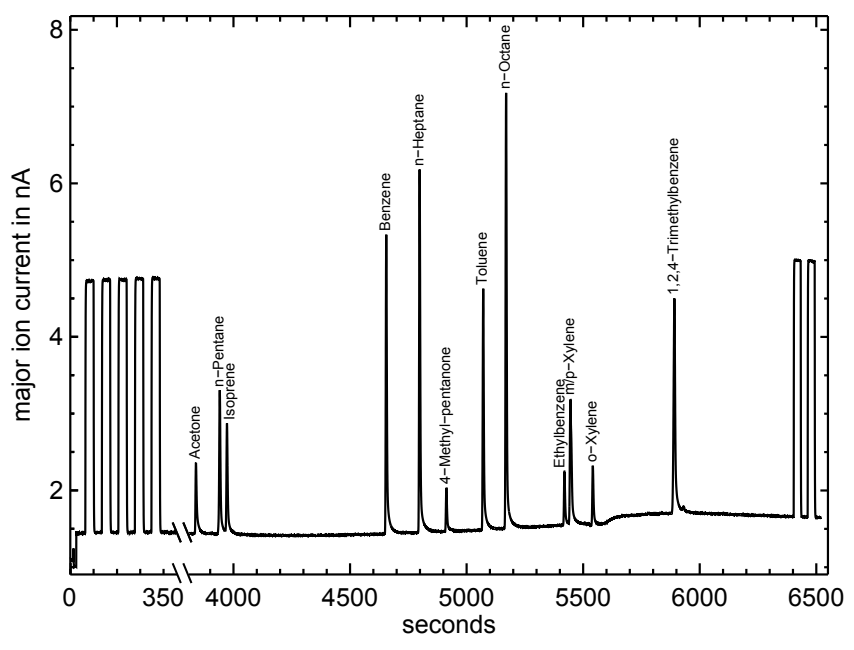

Figure 2. Example of an IRMS chromatogram (major signal) of the VOC test mixture. Working reference gas peaks are added at the beginning ( 5 peaks) and the end ( 2 peaks) of every chromatogram.

$\mathrm{CO}_{2}$ ), which freezes out in the CIS and blocks the liner. As the ${ }^{2} \mathrm{H} /{ }^{1} \mathrm{H}$ analysis of ambient VOCs needs sample volumes of about $200 \mathrm{~L}(160 \mathrm{mg} \mathrm{CO}$ at $400 \mathrm{ppmV}$ ) this configuration is no longer suitable for measurements of ambient air. Therefore, we changed the adsorbent material from glass beads to Tenax ${ }^{\circledR} \mathrm{TA}$ (configuration B). The $\delta^{2} \mathrm{H}$ values of the VOC test mixture $\left(\mathrm{CO}_{2}\right.$-free) were determined in both configurations (Fig. 3). Although for some compounds (isoprene, $n$-heptane, xylenes) slight differences between both configurations were observed, there is a good agreement within the standard deviations. When evaluating the differences, it should be noted that part of this deviation is obviously due to a change in the $\mathrm{H}_{3}^{+}$factor because of a necessary renewal of the filament between both measurement series. Moreover, the standard deviations (size of the boxes) indicate that the measurements using Tena ${ }^{\circledR} \mathrm{TA}$ show a higher precision than those using glass beads. First test measurements of ambient air (see Sect. 3.5) showed that using configuration B measurements of sample volumes up to $200 \mathrm{~L}$ are possible without difficulty.

\subsection{Reproducibility, stability, linearity and detection limit}

Regarding reproducibility, stability, and linearity two cases have to be addressed. On the one hand, stability and linearity of the IRMS are regularly controlled using the working reference gas. On the other hand, reproducibility and linearity of the complete measurement set-up was verified using the VOC test mixture. In the case of stability tests of the IRMS, 10 working reference gas peaks are produced using the reference gas injector box and $\delta^{2} \mathrm{H}$ values are calculated for each peak. The standard deviation of these 10 measurements is lower than $0.3 \%$ (in terms of $\delta$-values). Linearity tests are performed by injecting the working reference gas at differ- 
Table 1. Compounds contained in the VOC test mixture, volumes of the liquids injected into the gas cylinder and final mixing ratios. For comparison the hydrogen isotope ratios and standard deviations obtained by our GC-P-IRMS as well as the results of EA (Agroisolab) of the pure liquids are shown. Furthermore, the minimum compound mass to yield stable isotope ratios is given in ng.

\begin{tabular}{lrrrrr}
\hline Compounds & Volume in $\mu \mathrm{L}$ & Mixing ratio in $\mathrm{ppb}$ & $\delta^{2} \mathrm{H} / \% \circ$ & Agroisolab & $\begin{array}{r}\text { Minimum } \\
\text { compound mass } \\
\text { in ng }\end{array}$ \\
\hline$n$-Pentane & & & & & 150 \\
$n$-Heptane & 6.73 & $306 \pm 19$ & $-139.7 \pm 7.6$ & $-146.6 \pm 1.3$ & 360 \\
Toluene & 9.35 & $406 \pm 34$ & $-103.2 \pm 2.1$ & $-98.4 \pm 1.1$ & 310 \\
$\begin{array}{l}1,2,4 \text {-Trimethylbenzene } \\
\text { 4-Methyl-2-pentanone }\end{array}$ & 8.60 & $508 \pm 42$ & $-69.7 \pm 2.5$ & $-68.9 \pm 0.5$ & $\mathrm{n} / \mathrm{a}$ \\
Xylenes +Ethylbenzene* & 11.21 & $373 \pm 58$ & $-43.1 \pm 5.4$ & $-64.0 \pm 0.5$ & 190 \\
$m / p$-Xylene & 9.35 & $\mathrm{n} / \mathrm{a}$ & $-186.5 \pm 8.7$ & $-178.1 \pm 1.2$ & 120 \\
$o$-Xylene & 9.91 & & & $-83.8 \pm 1.1$ & 110 \\
Ethylbenzene & & $263 \pm 15$ & $-87.6 \pm 2.2$ & & 240 \\
Isoprene & & $104 \pm 11$ & $-26.1 \pm 12$ & & 310 \\
$n$-Octane & $92 \pm 8$ & $-46.9 \pm 7.1$ & & $-102.8 \pm 0.9$ & \\
\hline
\end{tabular}

* Xylenes and ethylbenzene are one liquid mixture and thus only one $\delta^{2} \mathrm{H}$ value can be measured by EA.

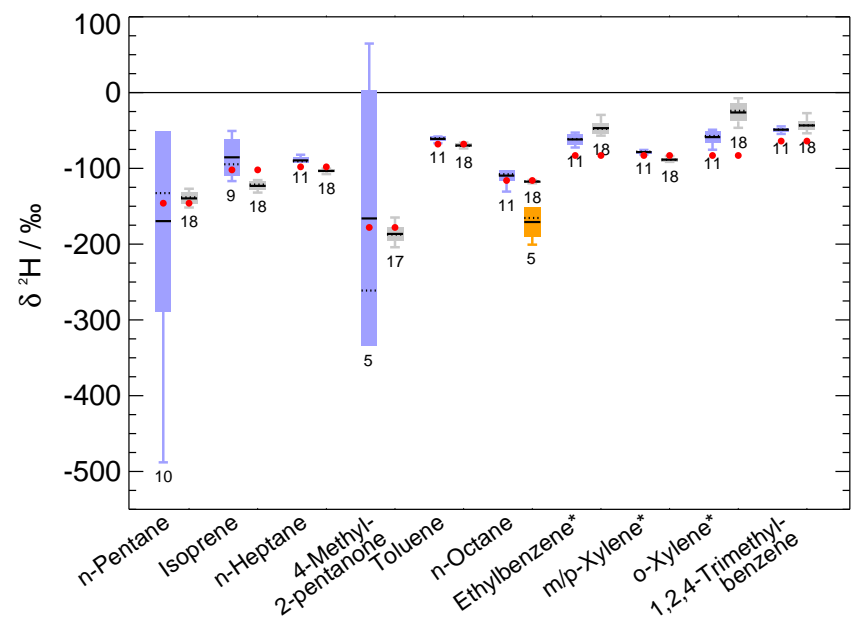

Figure 3. Compound-specific $\delta^{2} \mathrm{H}$ in different VOCs adsorbed on glass beads (blue boxes) and Tenax ${ }^{\circledR} \mathrm{TA}$ (grey boxes), respectively. The size of each box represents the standard deviation, minimum and maximum values are indicated by the whiskers, solid and dashed black lines mark the mean and median value, respectively. The numbers below the boxes indicate the corresponding number of measurements. The values obtained by Agroisolab are represented as red dots. The orange box represents the mean value and standard deviation of $\delta^{2} \mathrm{H}$ of $n$-octane measured while a degrading of the conditioning of the ceramic tube in the pyrolysis oven is observed (see Sect. 3.3.1) (*not comparable to the results of Agroisolab); see text for more detail.

ent pressure levels resulting in different peak heights ( 0.3 to $5 \mathrm{nA}$ in the major signal). The variation of the calculated $\delta^{2} \mathrm{H}$ values is lower than $0.4 \% o \mathrm{nA}^{-1}$.

Following the verification that Tenax ${ }^{\circledR} \mathrm{TA}$ is a suitable adsorbent the reproducibility and linearity of the complete sys- tem was verified by several individual measurements of the VOC test mixture.

In case of the reproducibility test, 18 individual measurements of the diluted VOC test mixture were performed. The obtained standard deviations in $\delta^{2} \mathrm{H}$ values are better than $2.5 \%$ for $n$-heptane, toluene, $n$-octane, and $m / p$-xylene, and better than $9 \%$ for all other compounds except $o$-xylene $(12 \%)$. These results show (at least for the compounds investigated) that the system is well-suited to achieve the precision necessary to identify hydrogen isotopic effects in ambient VOCs. Comparison of the mean $\delta^{2} \mathrm{H}$ values and the $\delta^{2} \mathrm{H}$ values obtained by the bulk analysis of the primary compounds by Agroisolab shows a good agreement within the standard deviations of our measurements and the uncertainties given by Agroisolab for $n$-pentane, 4-methyl-pentane2-one (4-methyl-2-pentanone), toluene, and $n$-octane (Fig. 3 and Table 1). The uncertainties given by Agroisolab are the standard deviation of the measurements and the uncertainties of three secondary standards used for the calibration. The differences between both mean values are lower than $5 \%$ for $n$-heptane, toluene, and $n$-octane and lower than $9 \%$ for $n$ pentane and 4-methyl-2-pentanone. A larger difference of 15 and $20 \%$ is only evident for 1,2,4-trimethylbenzene and isoprene, respectively. A direct comparison of $\delta^{2} \mathrm{H}$ values of the xylenes and ethylbenzene is not possible because only a mixture of these compounds was at our disposal. Thus, using EA, Agroisolab could only determine the bulk $\delta^{2} \mathrm{H}$ value of this mixture.

To identify possible non-linearity effects of the complete system the VOC test mixture was measured with different stages of dilution. From this measurement series, we additionally derived the minimum required peak areas to obtain reproducible $\delta^{2} \mathrm{H}$ values. The isotope ratios are plotted against the peak area for each compound and the required 


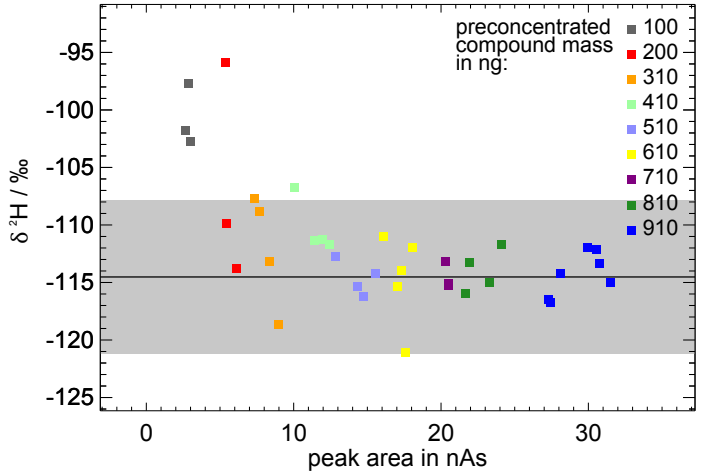

Figure 4. In order to estimate the required minimum mass of the substances to yield stable isotope ratios, the isotope ratios are plotted against the peak area (here using the example of $n$-octane). Mean value and $3 \sigma$ interval calculated by using values with stable isotope ratios (here above $8 \mathrm{nAs}$ ) are represented as black solid line and grey shaded area, respectively. The pre-concentrated mass of $n$-octane is colour coded. For $n$-octane the minimum required mass is estimated to $310 \mathrm{ng}$ corresponding to about $50 \mathrm{ng}$ hydrogen.

minimum peak area can be estimated. Using the example of $n$-octane this peak area is about $8 \mathrm{nAs}$ (cf. Fig. 4). With lower peak areas, the calculated isotope ratios begin to appear outside of the grey shaded area, which remarks the $3 \sigma$ interval of the mean value. This mean value and standard deviation is calculated using only values corresponding to peak areas larger than $8 \mathrm{nAs}$. Finally, the minimum mass of the substance to yield stable isotope ratios can be derived from the respective stage of dilution and mixing ratio in the VOC test mixture. In the case of $n$-octane the minimum mass is about $310 \mathrm{ng}$. This procedure is done for every measured compound and the required minimum masses are given in Table 1. Furthermore, the minimum mass of hydrogen required to yield stable isotope ratios can be calculated resulting in about 50 ng hydrogen.

\subsection{Influence of the pyrolysis system (ceramic tube) on the $\delta^{2} H$ values}

\subsubsection{Carbon conditioning}

During the pyrolysis of VOCs, ${ }^{1} \mathrm{H}_{2}$ and ${ }^{1} \mathrm{H}^{2} \mathrm{H}$ are formed and elemental carbon is deposited on the inner surface of the pyrolysis tube. This carbon layer seems to be essential for an efficient production of ${ }^{1} \mathrm{H}_{2}$ and ${ }^{1} \mathrm{H}^{2} \mathrm{H}$. According to the recommendation of the manufacturer (Isoprime) the ceramic tube has to be carbon conditioned before the first use by flushing the tube with a light hydrocarbon in order to coat the inner surface with carbon. Following this first conditioning step, this carbon layer resulting from repeated measurements of VOCs, was said to be sufficient to sustain the conditioning of the pyrolysis tube. The first conditioning was performed using propane added to the sample line helium, but in contrast to the recommendation, the conditioning seems

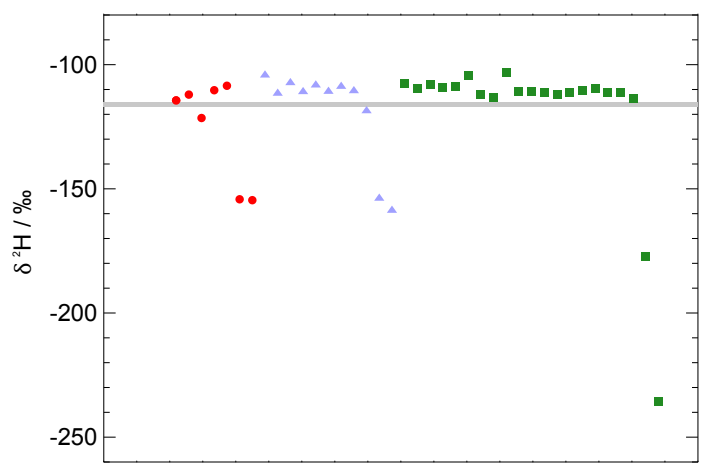

Figure 5. A step in $\delta^{2} \mathrm{H}$ values was apparent after 6 measurements, when the ceramic tube was conditioned for $5 \mathrm{~min}$, after 10 measurements, when conditioned for $10 \mathrm{~min}$, and after 20 measurements, when conditioned for $20 \mathrm{~min}$. The measurements after conditioning for $5 \mathrm{~min}$ are represented by red dots, measurements after conditioning for $10 \mathrm{~min}$ by blue triangles and measurements after $20 \mathrm{~min}$ by green squares. The grey bar shows the value obtained by elemental analysis (EA) (Agroisolab), where the thickness of the bar is equal to the uncertainty given by Agroisolab. This effect is observed for all measured substances and shown here for $n$-octane as an example.

to decline very rapidly with increasing number of measurements. Our results show that the carbon layer resulting from repeated measurements of VOCs seems to be insufficient to maintain the conditioning of the pyrolysis tube. As a result, considerable fluctuations in the $\delta^{2} \mathrm{H}$ values occur indicating a significant influence of the status of the pyrolysis tube. Figure 5 shows three measurement series using $n$-octane as an example. As can be seen, after a certain number of measurements a noticeable step in the $\delta^{2} \mathrm{H}$ values occurs towards significantly lower $\delta^{2} \mathrm{H}$ values. This step is observed for all measured compounds. After a re-conditioning of the tube, all measured $\delta^{2} \mathrm{H}$ values are at the same level as before. It appears that the durability of the conditioning depends on the number of measurements rather than on time. When conditioning the ceramic tube for 5, 10 and $20 \mathrm{~min}$, the step in $\delta^{2} \mathrm{H}$ values arises after 6,10 and 20 measurements, respectively. The $\delta^{2} \mathrm{H}$ values before the step fit obviously quite well to the results of the bulk analysis by Agroisolab. Furthermore, the standard deviations of the $\delta^{2} \mathrm{H}$ values of all analysed compounds increase significantly after the step (in the case of $n$ octane from $1.3 \%$ o before to $19.8 \%$ after the step). For these reasons, we consider the $\delta^{2} \mathrm{H}$ values before the step to be more reliable. The increasing standard deviation in $\delta^{2} \mathrm{H}$ after the step is shown in Fig. 3 using the example of $n$-octane. The grey box represents the results of the reproducibility experiments with a well-conditioned tube, the orange box represents results measured after the step was observed. As a consequence, regular measurements of the VOC test mixture are essential not only for calibration purposes but also to verify the conditioning of the pyrolysis tube when measuring unknown air samples. 
Our observations are in contrast to the observations reported by Brass and Röckmann (2010), who state that an extensive carbon conditioning may even have a negative effect on the formation of hydrogen molecules, and repeated measurements of VOCs are sufficient to condition the pyrolysis tube. The reason for this obviously different behaviour may be due to the different pyrolysis tubes used (silica vs. aluminium oxide). In any case, these details should be subject of further investigations.

Brass and Röckmann (2010) also report on the influence of $\mathrm{H}_{2} \mathrm{O}$ on the pyrolysis of methane. Our results confirm this observation. When measuring ambient air the step in $\delta^{2} \mathrm{H}$ values is observed much earlier (after only four measurements, when conditioning for $20 \mathrm{~min}$ ) most probably due to a higher amount of water entering the system and the ceramic tube. A possible process reducing the carbon layer is that oxygen atoms from water molecules react with the carbon to $\mathrm{CO}$ and $\mathrm{CO}_{2}$. Because $\mathrm{H}_{2} \mathrm{O}$ is also a source of protonation and can lead to an increase in $\mathrm{H}_{3}^{+}$formation, we therefore changed the chromatographic method to avoid that any $\mathrm{H}_{2} \mathrm{O}$ enters the pyrolysis oven. It turned out that the conditioning is sustained for many more measurements when applying this method.

Kornexl et al. (1999) reported on reactions of oxygen from the ceramic tube with sample compounds because of an oxygen self-diffusion in $\mathrm{Al}_{2} \mathrm{O}_{3}$. If these reactions affect the abundance of ${ }^{1} \mathrm{H}_{2}$ and ${ }^{1} \mathrm{H}^{2} \mathrm{H}$, this could be an explanation of the observed variation in $\delta^{2} \mathrm{H}$ values when the carbon layer is degrading. Another source of oxygen, which is unavoidable when analysing ambient VOCs, is the presence of oxygenated compounds. However, due to the low amount of these compounds, this effect may be of minor importance, but still has to be verified in the future.

In order to get an impression of the carbon layer, we inspected the surface condition of parts of a used ceramic tube at different positions (outside and inside the heated area) using a scanning electron microscope (SEM). The part of the tube located outside of the hot area shows the typical structure of a more or less clean $\mathrm{Al}_{2} \mathrm{O}_{3}$ surface (cf. Fig. 6a). The part located inside the hot area shows a different texture indicating a carbon layer covering the $\mathrm{Al}_{2} \mathrm{O}_{3}$ surface. However, also some of the carbon seems to have been deposited in soot-like structures which obviously do not cover the ceramic surface completely (cf. Fig. 6b). At present, we do not have a definite interpretation of the pictures. The pictures show, however, that the carbon layer is either not as uniform as expected or changes dramatically during the use of the pyrolysis tube.

\subsubsection{Pyrolysis temperature}

A further source for errors in the stable isotope ratios of hydrogen in VOCs is the potential formation of methane during the pyrolysis process. Burgoyne and Hayes (1998) reported on the formation of methane as an intermediate product in the pyrolysis of VOCs depending on the pyrolysis temperature.
They investigated the methane formation during the pyrolysis of propane and showed that formation of methane starts at a temperature of about $530 \mathrm{~K}$, peaks at about $700 \mathrm{~K}$ and stops at temperatures above $1100 \mathrm{~K}$. A methane production would directly affect the ratio of ${ }^{2} \mathrm{H} /{ }^{1} \mathrm{H}$ and thus distort the stable isotope ratios of the investigated VOCs. Furthermore, methane is a source for protonation. Any methane getting in the ion source of the IRMS may lead to higher $\mathrm{H}_{3}{ }^{+}$production, which again influences the calculated isotope ratios (Brand, 2004). Therefore, we determined the optimum temperature for the pyrolysis process to allow for a quantitative conversion of the hydrogen atoms of the VOCs to hydrogen molecules with a specific measurement series.

Because the recommended temperature for the pyrolysis process in the ceramic tube $\left(\mathrm{Al}_{2} \mathrm{O}_{3}\right)$ is $1723 \mathrm{~K}$, we performed measurements at pyrolysis temperatures of $1173,1273,1473$ and $1723 \mathrm{~K}$, respectively. Temperatures were not set to values higher than $1723 \mathrm{~K}$ to avoid operating the oven too close to its maximum temperature of $1773 \mathrm{~K}$. In this measurement series ${ }^{1} \mathrm{H}_{2}$ and ${ }^{1} \mathrm{H}^{2} \mathrm{H}$ signals were measured and $\delta^{2} \mathrm{H}$ values were derived. In a second step the IRMS was tuned to the mass of $\mathrm{CH}_{4}$ to measure the methane signal at the temperatures given above. The results are shown in Fig. 7 using a normalisation for better comparison. For each compound the peak areas at all temperatures are summarised to a total peak area. For each compound and each temperature the corresponding peak area is normalised to this total peak area. The grey $\left(\mathrm{CH}_{4}\right)$ and blue $\left({ }^{1} \mathrm{H}_{2}\right)$ bars cover the range of results for all measured compounds including their standard deviations. As a specific example, the values of $n$-octane are presented as black squares. The methane signal peaks in the temperature range between 1173 and $1273 \mathrm{~K}$, whereas the ${ }^{1} \mathrm{H}_{2}$ signal has a maximum in the temperature range between 1673 and $1723 \mathrm{~K}$. Thus, our results are very similar to those obtained by Burgoyne and Hayes (1998). At $1723 \mathrm{~K}$ the methane signal was below the lower limit of detection. Below $1173 \mathrm{~K}$ no ${ }^{1} \mathrm{H}_{2}$ is produced and thus no ${ }^{1} \mathrm{H}_{2}$ signal is detectable. Furthermore, at a pyrolysis temperature of $1723 \mathrm{~K}$ the $\delta^{2} \mathrm{H}$ values of all compounds are very stable with the standard deviations presented above.

\subsection{Influence of $\mathrm{H}_{3}^{+}$on $\delta^{2} \mathrm{H}$ values}

$\mathrm{H}_{3}^{+}$ions are formed in the ion source of the IRMS by collision of ${ }^{1} \mathrm{H}_{2}^{+}$ions with ${ }^{1} \mathrm{H}_{2}$ molecules (Sessions et al., 2001b). Because $\mathrm{H}_{3}^{+}$ions have the same mass to charge ratio as ${ }^{1} \mathrm{H}^{2} \mathrm{H}$ ions they increase the minor signal. As mentioned above, the software package automatically corrects for the $\mathrm{H}_{3}^{+}$contribution using $\mathrm{a}_{3}^{+}$factor. This factor is determined by a method similar to the stability and linearity tests of the IRMS described above. Four working reference gas peaks at different pressure levels are measured and the amount of $\mathrm{H}_{3}^{+}$is calculated by comparing both the minor and major signals at these pressure levels. As the formation of $\mathrm{H}_{3}^{+}$in the ion source depends on the pressure of ${ }^{1} \mathrm{H}_{2}$, the contribution of $\mathrm{H}_{3}^{+}$ions 

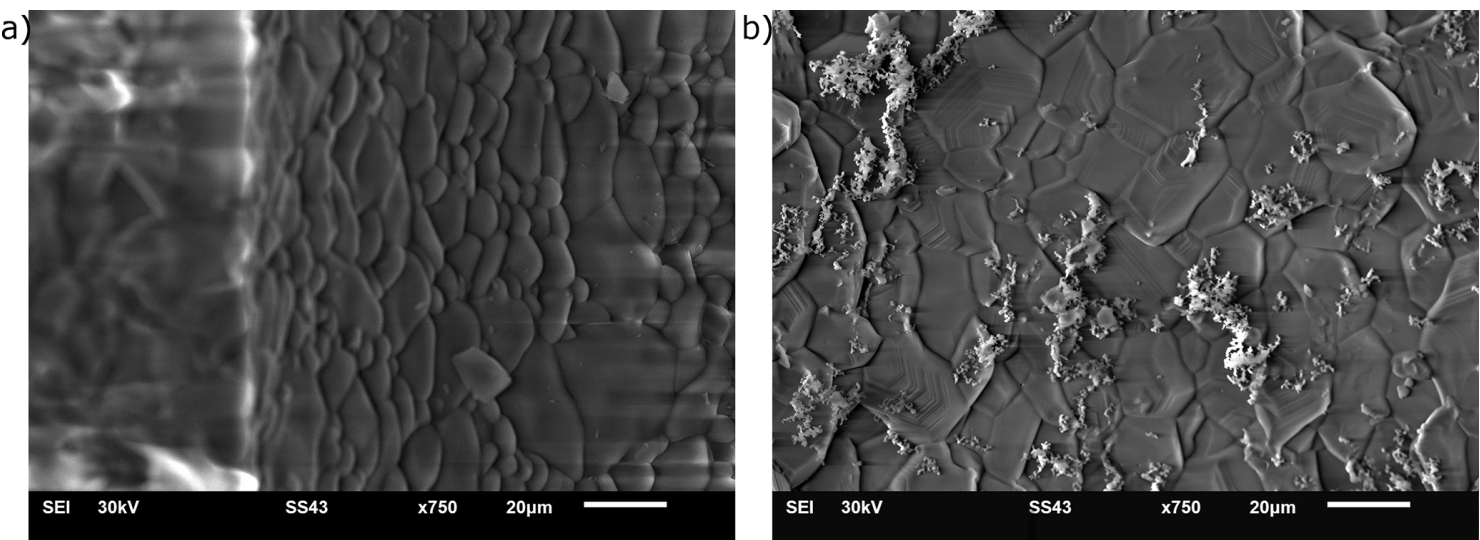

Figure 6. Scanning electron microscope (SEM) pictures of the inner surface of a ceramic tube at two different positions. (a) shows a part located outside of the hot area, where the typical structure of $\mathrm{Al}_{2} \mathrm{O}_{3}$ (ceramic) can be seen. (b) shows a part located inside the hot area $(1723 \mathrm{~K})$, where the ceramic is obviously partly covered with structures that might originate from carbon. Both pictures are taken with a magnification of 750 .

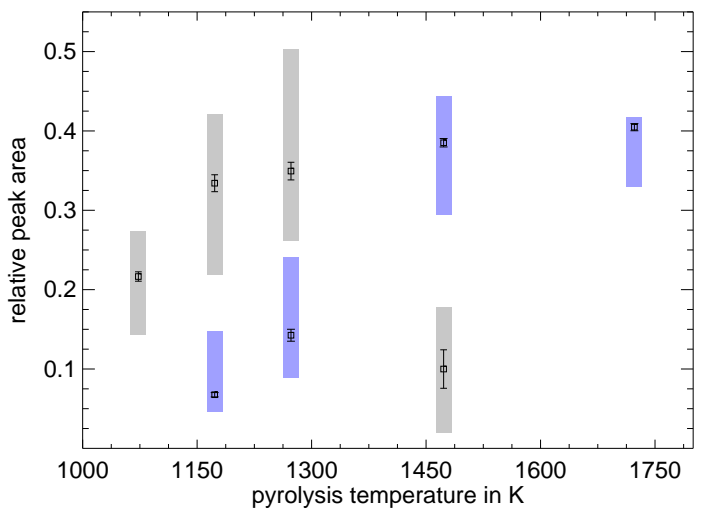

Figure 7. ${ }^{1} \mathrm{H}_{2}$ (blue bars) and $\mathrm{CH}_{4}$ (grey bars) signals measured with the IRMS are shown in relative units (see text for more detail) for different pyrolysis temperatures. The bars represent results for all measured compounds including standard deviations. As an example results of $n$-octane are shown by black squares including standard deviation (error bars).

to the ${ }^{1} \mathrm{H}^{2} \mathrm{H}$ signal can be determined by comparing the increase in both signals with increasing pressure of the working reference gas. One of the basic requirements is that this factor is stable (variation of only 0.1). During the measurement series reported here the determined $\mathrm{H}_{3}^{+}$factor ranged from 5.1 to 5.7 and thus was not as constant as expected. To analyse to what extent the $\delta^{2} \mathrm{H}$ values were affected by this variation when using CFDP, the same measurement series was analysed using $\mathrm{H}_{3}^{+}$factors of 5.0, 5.3 and 5.8. As can be seen from Fig. $8, \delta^{2} \mathrm{H}$ values change with larger $\mathrm{H}_{3}^{+}$factors, because a larger factor means that a larger part of the mass 3 signal is assumed to originate from $\mathrm{H}_{3}^{+}$ions. Thus, the ratios of ${ }^{2} \mathrm{H} /{ }^{1} \mathrm{H}$ become smaller and consequently the $\delta^{2} \mathrm{H}$ values change depending on the size and corrections of the working reference gas and sample signals (cf. Eq. 1). The use of the

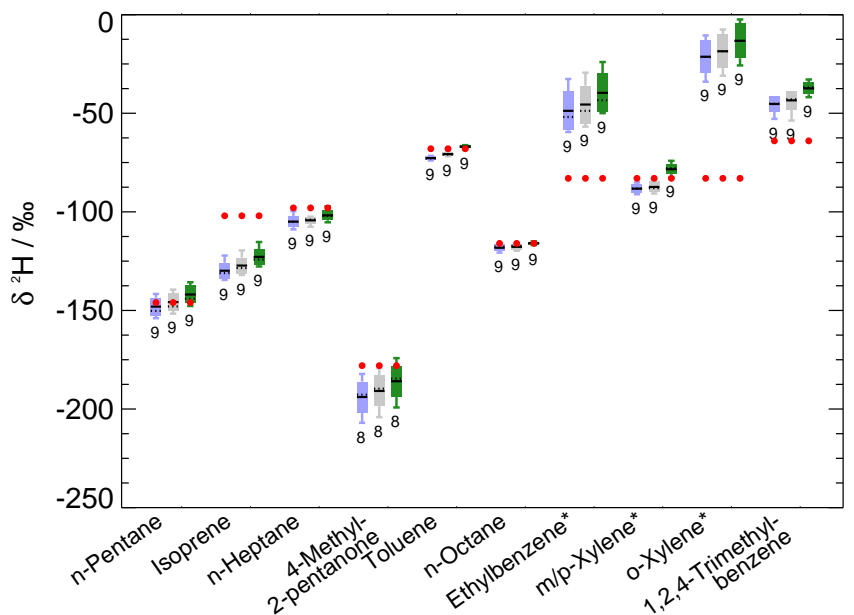

Figure 8. The same measurement series was analysed 3 times using $\mathrm{H}_{3}^{+}$factors of 5.0 (grey boxes), 5.3 (blue boxes) and 5.8 (green boxes). For comparison the results of EA (Agroisolab) are presented as red dots. The whisker plot is as in Fig. 3 (*not comparable to the results of Agroisolab); see text for more detail.

different $\mathrm{H}_{3}^{+}$factors results in differences in the mean $\delta^{2} \mathrm{H}$ values from $2 \%$ ( $n$-octane) to $10 \%$ o $(m / p$-xylene), which is slightly larger than the standard deviations presented above. Thus, this influence has to be taken into account when considering uncertainties.

\subsection{First test measurements of ambient air}

Applying the new chromatographic method in order to avoid any water getting into the pyrolysis oven and with regular verifications of the conditioning of the ceramic tube, first test measurements of ambient air have been performed. For these test measurements, ambient air was sampled on 5 different 
days in February and March 2015 from outside the institute's building through a PFA tube connected to the sample inlet of the TDSG-L. The university campus is located in the centre of Wuppertal and one of the major sources of VOCs is obviously vehicle exhaust. Focussing on the compounds contained in the VOC test mixture, the required peak areas in ambient air can be achieved with sample volumes of $200 \mathrm{~L}$ at least for $n$-pentane, toluene, ethylbenzene, and $o$ - and $\mathrm{m} / \mathrm{p}$ xylene. Regarding the required peak areas, six measurements were selected and further analysed using the same method as for the characterisation measurements. The obtained $\delta^{2} \mathrm{H}$ values range from -136 to $-105 \%$ o for $n$-pentane, from -86 to $-63 \%$ for toluene, from -39 to $-15 \%$ o for ethylbenzene, from -99 to $-68 \%$ for $m / p$-xylene, and from -45 to $-34 \%$ o for $o$-xylene. It should be noted that these $\delta^{2} \mathrm{H}$ values result from a sampling time of 145 min per measurement. As mentioned before, to our knowledge the only other published $\delta^{2} \mathrm{H}$ values of atmospheric VOCs at ambient levels were reported by Kikuchi and Kawashima (2013). They measured $\delta^{2} \mathrm{H}$ values in benzene and toluene in roadside air ranging from -174.4 to $-74.9 \%$ and from -134.7 to $-35.0 \%$, respectively. Compared to their results, our $\delta^{2} \mathrm{H}$ values of toluene fit into the range given by Kikuchi and Kawashima (2013). The smaller range of our results may be attributed to different sources and production processes of the fuel used in Japan and Europe. We can further compare our results to the measurements of toluene, ethylbenzene, $m$-xylene, and $o$-xylene in car emissions by von Eckstaedt et al. (2011a). They measured $\delta^{2} \mathrm{H}$ values of different VOCs in diesel and petrol car emissions. Their results for diesel car emissions are $(-3 \pm 8)$, $(-70 \pm 14)$, and $(-49 \pm 12) \%$ o for toluene, $m$-xylene, and $o$ xylene, respectively. The results for petrol car emissions are $(-65 \pm 3),(-47 \pm 4),(-61 \pm 3)$ and $(-48 \pm 4) \%$ for toluene, ethylbenzene, $m$-xylene and $o$-xylene, respectively. Our $\delta^{2} \mathrm{H}$ values of toluene ( -86 to $-63 \%$ ), ethylbenzene ( -39 to $-15 \%$ ) and the xylenes (-99 to $-68 \%$ o for $m / p$-xylene and -45 to $-34 \%$ for $o$-xylene) are comparable to the results of this source study, confirming that emissions from vehicle exhaust dominated the composition of our samples. In summary, our first measurements demonstrate the suitability of our instrumental set-up for the measurements of $\delta^{2} \mathrm{H}$ values of VOCs at ambient conditions.

\section{Summary and outlook}

We set up and successfully characterised a new measurement system consisting of a GC-P-IRMS and a pre-concentration system to measure ${ }^{2} \mathrm{H} /{ }^{1} \mathrm{H}$ ratios in atmospheric VOCs at ambient levels. Using a test mixture the system was characterised concerning reproducibility and linearity. The obtained standard deviations calculated from 18 individual measurements are $<9 \%$ in $\delta^{2} \mathrm{H}$ values for $n$-pentane, $1,2,4$ trimethylbenzene, 4-methyl-2-pentanone, ethylbenzene and isoprene and even $\leq 2.5 \%$ o for $n$-heptane, toluene, $n$-octane and $m / p$-xylene. Thus, this system is suitable to identify ambient hydrogen isotopic effects. In addition, a comparison with results obtained by elemental analysis of the pure compounds shows a good agreement within our standard deviations for $n$-pentane, toluene, 4-methyl-2-pentanone and $n$ octane. Moreover, linearity experiments showed that reproducible measurements of $\delta^{2} \mathrm{H}$ values are possible with a preconcentrated mass of about $50 \mathrm{ng}$ hydrogen per substance. Furthermore, a pyrolysis temperature of $1723 \mathrm{~K}$ was found to be suitable regarding sufficient ${ }^{1} \mathrm{H}_{2}$ and ${ }^{1} \mathrm{H}^{2} \mathrm{H}$ production as well as prevention of methane production which would affect the measured $\delta^{2} \mathrm{H}$ values. The characterisation measurements showed a considerable influence of the pyrolysis process on $\delta^{2} \mathrm{H}$ values. The ceramic tube $\left(\mathrm{Al}_{2} \mathrm{O}_{3}\right)$ used for the pyrolysis process has to be regularly re-conditioned with a light hydrocarbon after a certain number of measurements to sustain a carbon layer on the inner surface of the tube. Otherwise considerable fluctuations in $\delta^{2} \mathrm{H}$ values occur. It is therefore necessary to verify the conditioning regularly with a test mixture when measuring unknown air samples. Considering this effect, first test measurements of ambient air were performed demonstrating the applicability of the system when using Tenax ${ }^{\circledR} \mathrm{TA}$ for VOC adsorption in the thermal desorption system of the pre-concentration unit. With sample volumes of $200 \mathrm{~L}$, which in this case were necessary to provide enough mass of hydrogen in order to meet the required detection limits, the measured $\delta^{2} \mathrm{H}$ values range from -136 to $-105 \%$ for $n$-pentane, from -86 to $-63 \%$ o for toluene, from -39 to $-15 \%$ for ethylbenzene, from -99 to $-68 \%$ for $m / p$-xylene and from -45 to $-34 \%$ o for $o$-xylene.

For prospective interpretation of ambient air measurements hydrogen kinetic isotope effects as well as model calculations concerning hydrogen isotope ratios are necessary. With a combination of stable hydrogen and stable carbon isotope ratios of atmospheric VOCs it may then be possible to reduce uncertainties in stable isotope studies of atmospheric VOCs.

Acknowledgements. Part of this work was funded by the German Sciences Foundation (DFG) under grant number KO 2340/4-1. We thank R. Kurtenbach and M. Gallus (chemistry department, atmospheric chemistry group, University of Wuppertal) for their help to prepare our VOC test mixture and for the measurements of the mixing ratios in this gas mixture. We further thank D. Lützenkirchen-Hecht (physics department, condensed matter group, University of Wuppertal) for his assistance to take SEM pictures of the ceramic tube. We thank Agroisolab, Jülich, Germany, for their measurements of $\delta^{2} \mathrm{H}$ values in the VOCs by elemental analysis.

Edited by: F. Keppler 


\section{References}

Archbold, M. E., Redeker, K. R., Davis, S., Elliot, T., and Kalin, R. M.: A method for carbon stable isotope analysis of methyl halides and chlorofluorocarbons at pptv concentrations, Rapid Commun. Mass Sp., 19, 337-342, doi:10.1002/rcm.1791, 2005.

Bi, X., Sheng, G., Liu, X., Li, C., and Fu, J.: Molecular and carbon and hydrogen isotopic composition of nalkanes in plant leaf waxes, Org. Geochem., 36, 1405-1417, doi:10.1016/j.orggeochem.2005.06.001, 2005.

Brand, W. A.: Mass spectrometer hardware for analyzing stable isotope ratios, in: Handbook of Stable Isotope Analytical Techniques, edited by: Groot, P. A. D., Elsevier, Amsterdam, chap. 38, 835-856, doi:10.1016/B978-044451114-0/50040-5, 2004.

Brass, M. and Röckmann, T.: Continuous-flow isotope ratio mass spectrometry method for carbon and hydrogen isotope measurements on atmospheric methane, Atmos. Meas. Tech., 3, 17071721, doi:10.5194/amt-3-1707-2010, 2010.

Brenninkmeijer, C. A. M., Janssen, C., Kaiser, J., Röckmann, T., Rhee, T. S., and Assonov, S. S.: Isotope effects in the chemistry of atmospheric trace compounds, Chem. Rev., 103, 5125-5162, doi:10.1021/cr020644k, 2003.

Burgoyne, T. W. and Hayes, J. M.: Quantitative production of $\mathrm{H}_{2}$ by pyrolysis of gas chromatographic effluents, Anal. Chem., 70, 5136-5141, doi:10.1021/ac980248v, 1998.

De Biévre, P., Gallet, M., Holden, N. E., and Barnes, I. L.: Isotopic abundances and atomic weights of the elements, J. Phys. Chem. Ref. Data, 13, 809-891, doi:10.1063/1.555720, 1984.

De Bortoli, M., Knöppel, H., Pecchio, E., Schauenburg, H., and Vissers, H.: Comparison of tenax and carbotrap for VOC sampling in indoor air, Indoor Air, 2, 216-224, doi:10.1111/j.16000668.1992.00004.x, 1992.

Duan, Y., Wu, B., Xu, L., He, J., and Sun, T.: Characterisation of n-alkanes and their hydrogen isotopic composition in sediments from Lake Qinghai, China, Org. Geochem., 42, 720-726, doi:10.1016/j.orggeochem.2011.06.009, 2011.

Gensch, I., Kiendler-Scharr, A., and Rudolph, J.: Isotope ratio studies of atmospheric organic compounds: principles, methods, applications and potential, Int. J. Mass Spectrom., 365-366, 206221, doi:10.1016/j.ijms.2014.02.004, 2014.

Goldstein, A. H. and Shaw, S. L.: Isotopes of volatile organic compounds: an emerging approach for studying atmospheric budgets and chemistry, Chem. Rev., 103, 5025-5048, doi:10.1021/cr0206566, 2003.

Greule, M., Huber, S. G., and Keppler, F.: Stable hydrogenisotope analysis of methyl chloride emitted from heated halophytic plants, Atmos. Environ., 62, 584-592, doi:10.1016/j.atmosenv.2012.09.007, 2012

Helmig, D. and Vierling, L.: Water adsorption capacity of the solid adsorbents Tenax TA, Tenax GR, Carbotrap, Carbotrap C, Carbosieve SIII, and Carboxen 569 and water management techniques for the atmospheric sampling of volatile organic trace gases, Anal. Chem., 67, 4380-4386, doi:10.1021/ac00119a029, 1995.

Hembeck, L.: Aufbau und Charakterisierung eines dynamischen Gasmischsystems zur Kalibrierung eines GaschromatographIsotopenverhältnis-Massenspektrometers (GC-IRMS), Bachelor Thesis, University of Wuppertal, Wuppertal, Germany, 49 pp., 2008.
Iannone, R., Anderson, R., Vogel, A., Rudolph, J., Eby, P., and Whiticar, M.: Laboratory studies of the hydrogen Kinetic Isotope Effects (KIES) of the reaction of non-methane hydrocarbons with the $\mathrm{OH}$ radical in the gas phase, J. Atmos. Chem., 47, 191-208, doi:10.1023/B:JOCH.0000021035.49613.f7, 2004.

Iannone, R., Anderson, R., Vogel, A., Eby, P., Whiticar, M., and Rudolph, J.: The hydrogen kinetic isotope effects of the reactions of n-alkanes with chlorine atoms in the gas phase, J. Atmos. Chem., 50, 121-138, doi:10.1007/s10874-005-2365-1, 2005.

Iannone, R., Koppmann, R., and Rudolph, J.: A technique for atmospheric measurements of stable carbon isotope ratios of isoprene, methacrolein, and methyl vinyl ketone, J. Atmos. Chem., 58, 181-202, doi:10.1007/s10874-007-9087-5, 2007.

Kikuchi, N. and Kawashima, H.: Hydrogen isotope analysis of benzene and toluene emitted from vehicles, Atmos. Environ., 72, 151-158, doi:10.1016/j.atmosenv.2013.02.029, 2013.

Kornexl, B. E., Gehre, M., Höfling, R., and Werner, R. A.: On-line $\delta^{18} \mathrm{O}$ measurement of organic and inorganic substances, Rapid Commun. Mass Sp., 13, 1685-1693, doi:10.1002/(SICI)10970231(19990830)13:16<1685::AID-RCM699>3.0.CO;2-9, 1999.

Liu, J., Geng, A., and Xiong, Y.: The application of stable carbon and hydrogen isotopic compositions of individual nalkanes to Paleozoic oil/source rock correlation enigmas in the Huanghua depression, China, J. Petrol. Sci. Eng., 54, 70-78, doi:10.1016/j.petrol.2006.07.003, 2006.

Redeker, K. R., Davis, S., and Kalin, R. M.: Isotope values of atmospheric halocarbons and hydrocarbons from Irish urban, rural, and marine locations, J. Geophys. Res.-Atmos., 112, D16307, doi:10.1029/2006JD007784, 2007.

Rice, A. L. and Quay, P.: Isotopic composition of formaldehyde in urban air, Environ. Sci. Technol., 43, 8752-8758, doi:10.1021/es9010916, 2009.

Rudolph, J.: Gas chromatography-isotope ratio mass spectrometry, in: Volatile Organic Compounds in the Atmosphere, edited by: Koppmann, R., chap. 10, Blackwell Publishing Ltd, Oxford, UK, 388-466, ISBN:978-1-4051-3115-5, 2007.

Rudolph, J., Müller, K., and Koppmann, R.: Sampling of organic volatiles in the atmosphere at moderate and low pollution levels, Anal. Chim. Acta, 236, 197-211, doi:10.1016/S00032670(00)83313-9, 1990.

Rudolph, J., Lowe, D. C., Martin, R. J., and Clarkson, T. S.: A novel method for compound specific determination of $\delta 13 \mathrm{C}$ in volatile organic compounds at ppt levels in ambient air, Geophys. Res. Lett., 24, 659-662, doi:10.1029/97GL00537, 1997.

Rudolph, J., Czuba, E., Norman, A., Huang, L., and Ernst, D.: Stable carbon isotope composition of nonmethane hydrocarbons in emissions from transportation related sources and atmospheric observations in an urban atmosphere, Atmos. Environ., 36, 11731181, doi:10.1016/S1352-2310(01)00537-4, 2002.

Rudolph, J., Anderson, R., Czapiewski, K., Czuba, E., Ernst, D., Gillespie, T., Huang, L., Rigby, C., and Thompson, A.: The stable carbon isotope ratio of biogenic emissions of isoprene and the potential use of stable isotope ratio measurements to study photochemical processing of isoprene in the atmosphere, J. Atmos. Chem., 44, 39-55, doi:10.1023/A:1022116304550, 2003.

Saito, T., Tsunogai, U., Kawamura, K., Nakatsuka, T., and Yoshida, N.: Stable carbon isotopic compositions of light hydrocarbons over the western North Pacific and implication for their 
photochemical ages, J. Geophys. Res.-Atmos., 107, ACH 2-1ACH 2-9, doi:10.1029/2000JD000127, 2002.

Saito, T., Kawamura, K., Tsunogai, U., Chen, T.-Y., Matsueda, H., Nakatsuka, T., Gamo, T., Uematsu, M., and Huebert, B. J.: Photochemical histories of nonmethane hydrocarbons inferred from their stable carbon isotope ratio measurements over east Asia, J. Geophys. Res.-Atmos., 114, D11303, doi:10.1029/2008JD011388, 2009.

Sessions, A. L., Burgoyne, T. W., and Hayes, J. M.: Determination of the $\mathrm{H}_{3}$ factor in hydrogen isotope ratio monitoring mass spectrometry, Anal. Chem., 73, 200-207, doi:10.1021/ac000488m, 2001a.

Sessions, A. L., Burgoyne, T. W., and Hayes, J. M.: Correction of $\mathrm{H}_{3}^{+}$contributions in hydrogen isotope ratio monitoring mass spectrometry, Anal. Chem., 73, 192-199, doi:10.1021/ac000489e, 2001b.

Thompson, A. E.: Stable Carbon Isotope Ratios of Nonmethane Hydrocarbons and Halocarbons in the Atmosphere, $\mathrm{PhD}$ thesis, York University Toronto, Toronto, Ontario, 299 pp., 2003.

Tsunogai, U., Yoshida, N., and Gamo, T.: Carbon isotopic compositions of $\mathrm{C}_{2}-\mathrm{C}_{5}$ hydrocarbons and methyl chloride in urban, coastal, and maritime atmospheres over the western North Pacific, J. Geophys. Res.-Atmos., 104, 16033-16039, doi:10.1029/1999JD900217, 1999. von Eckstaedt, C. V., Grice, K., Ioppolo-Armanios, M., Chidlow, G., and Jones, M.: $\delta \mathrm{D}$ and $\delta^{13} \mathrm{C}$ analyses of atmospheric volatile organic compounds by thermal desorption gas chromatography isotope ratio mass spectrometry, J. Chromatogr. A, 1218, 6511-6517, doi:10.1016/j.chroma.2011.06.098, 2011a.

von Eckstaedt, C. V., Grice, K., Ioppolo-Armanios, M., and Jones, M.: $\delta^{13} \mathrm{C}$ and $\delta \mathrm{D}$ of volatile organic compounds in an alumina industry stack emission, Atmos. Environ., 45, 5477-5483, doi:10.1016/j.atmosenv.2011.06.064, 2011 b.

Wintel, J., Hösen, E., Koppmann, R., Krebsbach, M., Hofzumahaus, A., and Rohrer, F.: Stable carbon isotope ratios of toluene in the boundary layer and the lower free troposphere, Atmos. Chem. Phys., 13, 11059-11071, doi:10.5194/acp-13-11059-2013, 2013.

Xiong, Y., Geng, A., Pan, C., Liu, D., and Peng, P.: Characterization of the hydrogen isotopic composition of individual nalkanes in terrestrial source rocks, Appl. Geochem., 20, 455-464, doi:10.1016/j.apgeochem.2004.09.014, 2005.

Yamamoto, S. and Kawamura, K.: Compound-specific stable carbon and hydrogen isotopic compositions of n-alkanes in urban atmospheric aerosols from Tokyo, Geochem. J., 44, 419-430, 2010.

Yeh, H.-W. and Epstein, S.: Hydrogen and carbon isotopes of petroleum and related organic matter, Geochim. Cosmochim. Ac., 45, 753-762, doi:10.1016/0016-7037(81)90046-6, 1981. 